\title{
The comparative analysis of the seismic test results performed using the cross-hole and down-hole methods in terms of test reliability and efficiency
}

\author{
Wojciech Tschuschke ${ }^{1}$, Stawomir Gogolik ${ }^{1, *}$, Maciej Kroll ${ }^{1}$ and Krzysztof Janicki ${ }^{2}$ \\ ${ }^{1}$ Institute of Construction and Geoengineering, Poznań University of Life Sciences, Poland \\ ${ }^{2}$ KGHM Polska Miedź („Polish Copper”) SA, Division Hydrotechnical Department, Poland
}

\begin{abstract}
Seismic tests are becoming more and more meaningful in modern geoengineering since they allow precise assessment of changes in the analyzed profile of soil deformation parameters at very small strain. The engineering practice generally uses two methods for such kinds of tests: reference cross-hole test and commercial down-hole method. The costs of implementation of this kind of research and the reliability of the results obtained along with any additional benefits from the type of the selected testing technique are not without significance. Seismic measurements for which comparative analysis was performed were carried out in a strongly anisotropic materials base of a tailings. The results of tests conducted with a standard cross-hole method were compared with those conducted using the down-hole method, in which the seismic piezocone (SCPTU) and seismic dilatometer (SDMT) were used. Test results have shown that in terms of assessment of their credibility, there were no fundamental differences in the quality of the recorded signals. It has been pointed out, however, that there are many advantages to penetration in situ tests, which complement identification of subsoil structure with many crucial elements that cannot be achieved using the cross-hole method.
\end{abstract}

Keywords: CHT, SCPTU, SDMT, comparative analysis, tailings

\section{Introduction}

The non-destructive seismic testing is one of the types of in situ geophysical tests used. In general, it relies on registration of the velocity of a particular type of seismic wave passing through the subsoil. Seismic test methods distinguish surface test techniques, which implement the phenomenon of seismic refraction (SR), as well as the in-hole testing techniques conducted between cross-holes (CHT) or down-holes (DHT) [1, 2]. Seismic measurements may be conducted as stand-alone test or in combination with another kind of in situ tests as the so-called combined test (invasive and non-destructive). According to the

\footnotetext{
* Corresponding author: s.gogolik@wp.pl
} 
elasticity theory, the seismic waves velocity can be used to determine the deformation modulus of the subsoil within the range of very small strain. The results of seismic surveys can be also used to analyze the distribution of the initial void ratio in issues related to the assessment of the liquefaction potential of the soil, as well as the identification of full saturation zones in the subsoil $[2,3]$. Due to the fact that the seismic signal in the subsoil propagates very quickly, which causes the measurement period to be very short, the precision of the measurement of the in situ seismic signal and the accuracy of the accepted interpretation method, i.e. time interval, are extremely important for the reliability of the test results. In the above context, the choice of an appropriate testing method may result in more or less precise identification of the subsoil parameters, which are determined based on the measurements of the seismic wave velocity. The primary aim of the study presented in the paper is comparison in terms of quality of seismic wave velocity test results.

\section{Investigation site}

Specialist seismic tests with the tested cross-hole (CHT) and down-hole (DHT) methods were carried out in the tailings massif deposited within the Mining Refuse Neutralisation Facility (MRNF) Żelazny Most. This facility has been operating for over 40 years and is used to accumulate tailings from processing copper ore while serving a key role in the management of process water and water from mine drainage. The scale of the facility, due to the amount of the accumulated waste, classifies it into the group of the world's largest hydraulic facilities (Fig. 1).

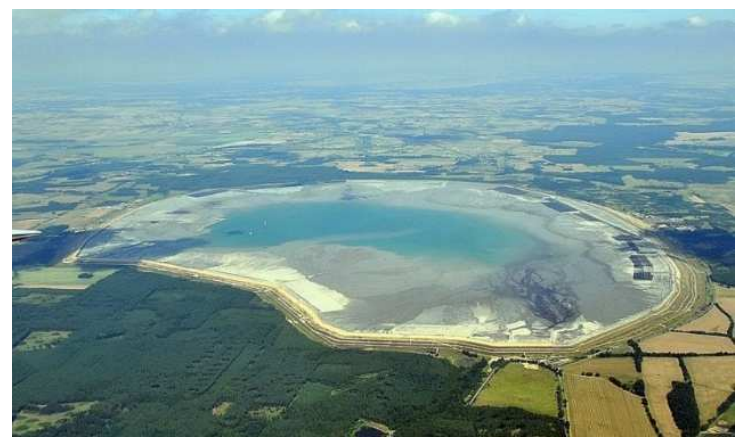

Fig. 1. Aerial view of the Żelazny Most depository, (https://polska-org.pl/783674,foto.html).

The storage facility area amounting to approximately 1400 ha is closed by the surrounding dams of a total length of about $14.3 \mathrm{~km}$. The pipelines distributing tailings with outlets which spigot the tailings that form the beach are located on the crown of the dams. The central part of the storage facility is the pond formed from the drained spigotted tailings. After over 40 years of the storage facility operation, as a result of progressive accumulation, it built up approximately 630 million $\mathrm{m}^{3}$ of tailings with continuously maintained overlying water of volume ranging between 5 million $\mathrm{m}^{3}$ and 7 million $\mathrm{m}^{3}$.

The waste material deposited in the facility, as a result of the process of spigotting accompanied by the tailings segregation process, can be distinguished by spatial variability of grain size and physical properties. The coarsest sandy material depositing on the beaches in the area where it is discarded is used to superstructure dams as filling of the bowl of the facility with tailings is taking place. Finer material flows along with the process water into the beach forming a number of silty laminations to dominate the construction profile of tailings in the pond area. The way the facility is superstructured, by the 'upstream' method, causes constantly higher dam embankments to be formed on the deposited material of increasingly inferior physical properties and lower bearing capacity $[4,5]$. 


\section{Methodology}

The researches of the seismic wave propagation velocity in the tailings massif were carried out using three measurement methods: cross-hole seismic testing (CHT) and cone penetration testing SCPTU, seismic dilatometer testing SDMT, classified as the down-hole methods (DHT). The CHT used an alternative method according to the standard ASTM 4428 with two boreholes (Fig. 2). The boreholes were made by drilling in a bentonite slurry and secured with a PVC casing pipe. The quality of the prepared boreholes have investigated by sonic logging method. This technique consist of the measurements of the velocity and propagation modes of the elastic waves in the materials surrounding the boreholes, with a penetration of few tens of centimetre around the hole.

In order to identify the geological-engineering conditions of the tailings massif, specialized seismic tests were performed within 18 research nodes. The nodes were positioned on the line of 6 cross-sections located within three dams: northern, eastern and western in the edge zone of the beach and of the embankments in the area of active impact of the circumferential beach drainage. Within each node a grid of research points of a projected rectangle was positioned by locating two drilled holes piped on the diagonal of the grid (CHT) and by setting in the other two corners of the grid space research for the downhole method using the seismic cone penetration testing (SCPTU) and seismic dilatometer testing (SDMT) (Fig. 2). Distances between particular test points within the node did not exceed $8 \mathrm{~m}$ (Fig. 3). The research was carried out at the bottom layer of the natural subsoil, which supports the tailings massif occurring at a depth of $40 \mathrm{~m}$ to $60 \mathrm{~m}$ depending on the location.

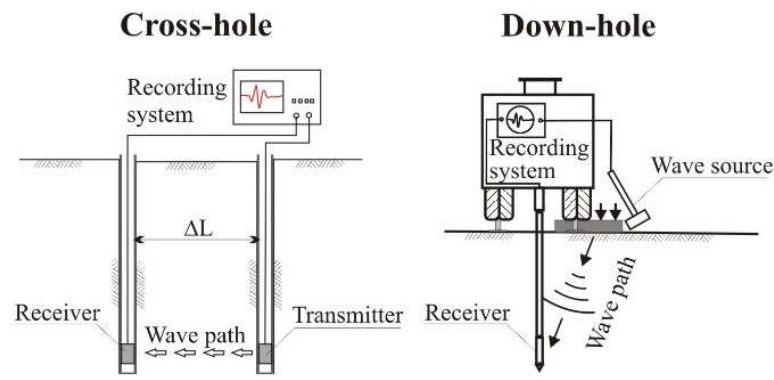

Fig. 2. Scheme of cross-hole and down-hole geophysical tests.

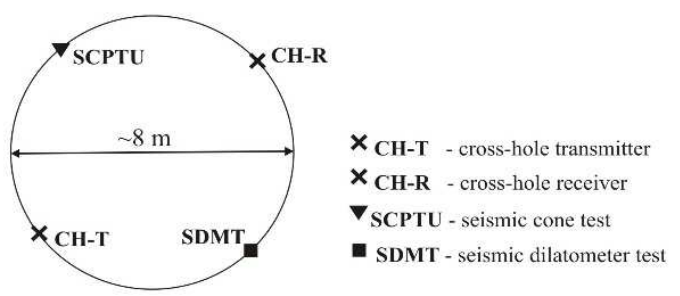

Fig. 3. Location of research points within the research node.

In the main studies, the source of the shear wave was the GEOS electrodynamic energizer. enabling to obtain vertical polarity waves $\left(\mathrm{S}_{\mathrm{hv}}\right)$ and horizontal polarity waves $\left(\mathrm{S}_{\mathrm{hh}}\right)$, whereas to generation the compression wave $(\mathrm{P})$ the Sparker source was put into practice. Various types of converters suitable for recording the dominant wave type were used as receivers. 
Wave velocity measurements were made at intervals of $1 \mathrm{~m}$ of the borehole depth increase. Each depth recorded 10 signals of the compression wave and 20 impulses of the vertically polarized shear wave signala (10 for positive and negative polarization). Signal acquisition was managed using the Win_CrossHole software developed by the SOLGEO company [6]. The system allowed the visualization and storage of all signals. In addition to estimating the period of real-time wave propagation, the system enabled averaging or stacking of the collected trace to obtain an signal quality. For precise determination of the velocity of the waves it was necessary to determine the exact distance between the source and the receiver. Such information was obtained by inclinometric measurements. The applied INCLIS-DH probe equipped with a three-axis magnetometer and a set of three accelerometers allowed to determine spatial deviations from the vertical axis of boreholes with depth. The propagation time of the compression wave from the source to the receiver determined the moment when the wave front arrived (first peak), whereas the shear wave crossing time was determined by the analysis of waves of the opposite polarity (Fig. 4).

The SCPTU tests employed the seismic cone, which in addition to the measurement of basic penetration parameters (cone resistance $-q_{c}$, friction sleeve $-f_{s}$ and pore water pressure $\left.-\mathrm{u}_{\mathrm{c}}\right)$, enable to determine the compression wave velocity $\left(\mathrm{V}_{\mathrm{p}}\right)$ and shear wave velocity in the subsoil $\left(\mathrm{V}_{\mathrm{s}}\right)[7,8]$. The cone used in the tests was equipped with two receivers of shear and compression wave, $0.5 \mathrm{~m}$ away. The wave source was a steel beam perpendicular to the axis of the penetrometer. In order to ensure good contact with the subsoil, the beam was pressed into the ground with the penetrometer leveling cylinders.
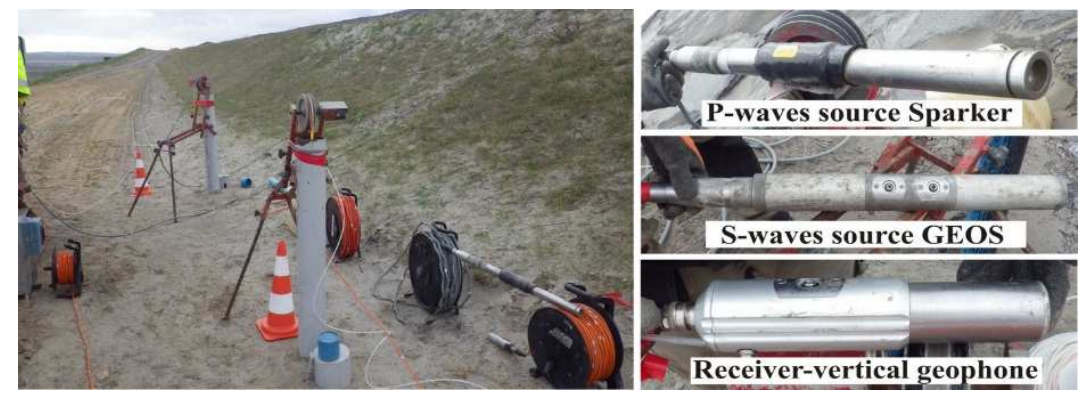

Fig. 4. Measurement system of CHT [6].

The SCPTU test was based on the pressing the piezocone into the subsoil at a constant speed and recording main penetration characteristics. At intervals of $1 \mathrm{~m}$, the penetration was stopped and the program module responsible for the seismic measurements was started. Hammer striking the beam caused the electric circuit to be closed and the wave to be registered allowing the determination of the time of wave propagation from the source to the geophone (Fig. 5).
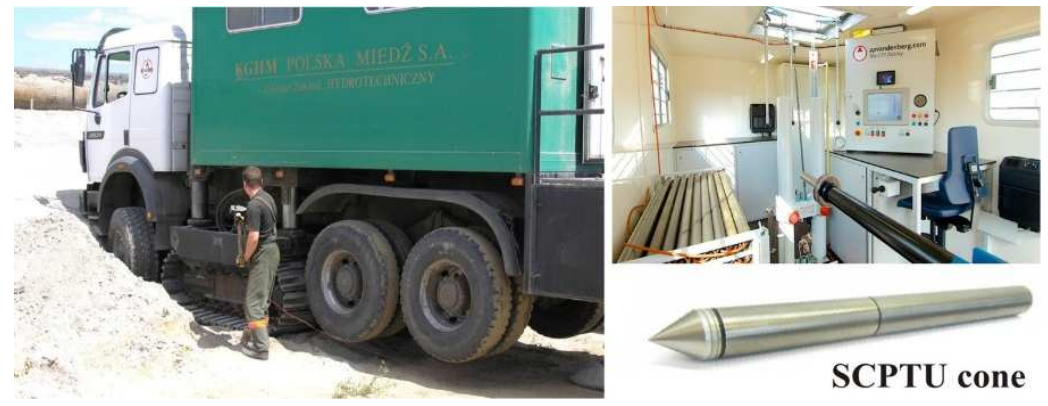

Fig. 5. Penetrometer and seismic piezocone. 
At the given depth, two measurements of the shear wave propagation time by horizontal impact to the left and right end of the beam and one measurement of the compression wave generated by the vertical hammer blow to the beam were performed. After confirming the obtained results, the seismic piezocone was pressed into the next set depth and the previously described procedure was repeated. The wave velocity in a given layer was determined based on the difference in the time of arrival of the wave and the distance traveled by the wave between adjacent depths of the conducted seismic tests (equation 1).

$$
V=\left(Z_{2}-Z_{1}\right) / \Delta T
$$

where: $\Delta \mathrm{T}$ - travel time, $\mathrm{Z}_{2}-\mathrm{Z}_{1}$ - distance of wave propagation

The time interval was determined by the cross-correlation method (Fig. 6).

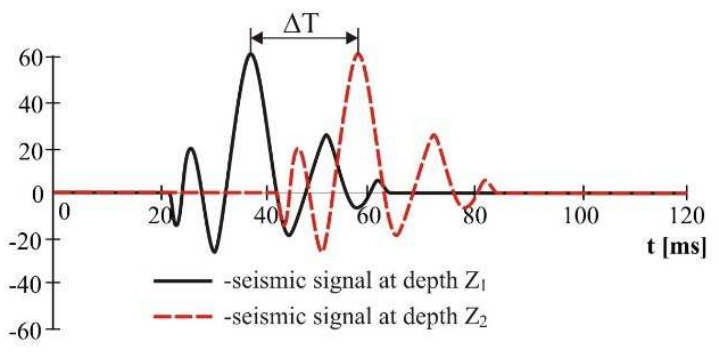

Fig. 6. Scheme of time interval determining, (t-time).

The SDMT test implemented the Marchetti seismic dilatometer which, in addition to the standard A and B pressure measurements, made it possible to determine the shear wave velocity $\left(\mathrm{V}_{\mathrm{s}}\right)[9,10]$. The device used two geophones placed at a distance of $0.5 \mathrm{~m}$ from each other, whereas the wave was generated using a pendulum hammer. The seismic tests were performed at $1 \mathrm{~m}$ interval and at every depth 3 to 5 repetitions of the wave velocity measurement were recorded (Fig. 7).
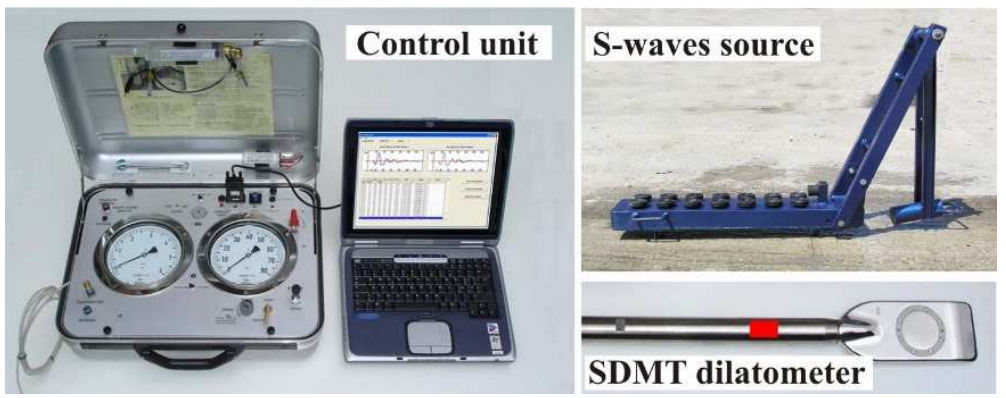

Fig. 7. SDMT measurement system [9].

\section{Results and analysis}

Regarding the fundamental questions of the reliability analysis of the seismic tests conducted with competing methods, the wave velocity distributions in the same test profiles were compared with depth. In the replication test, the cross-hole testing is limited only to the registration of seismic signals enabling determination of the shear and compression wave velocity (Fig. 8). 

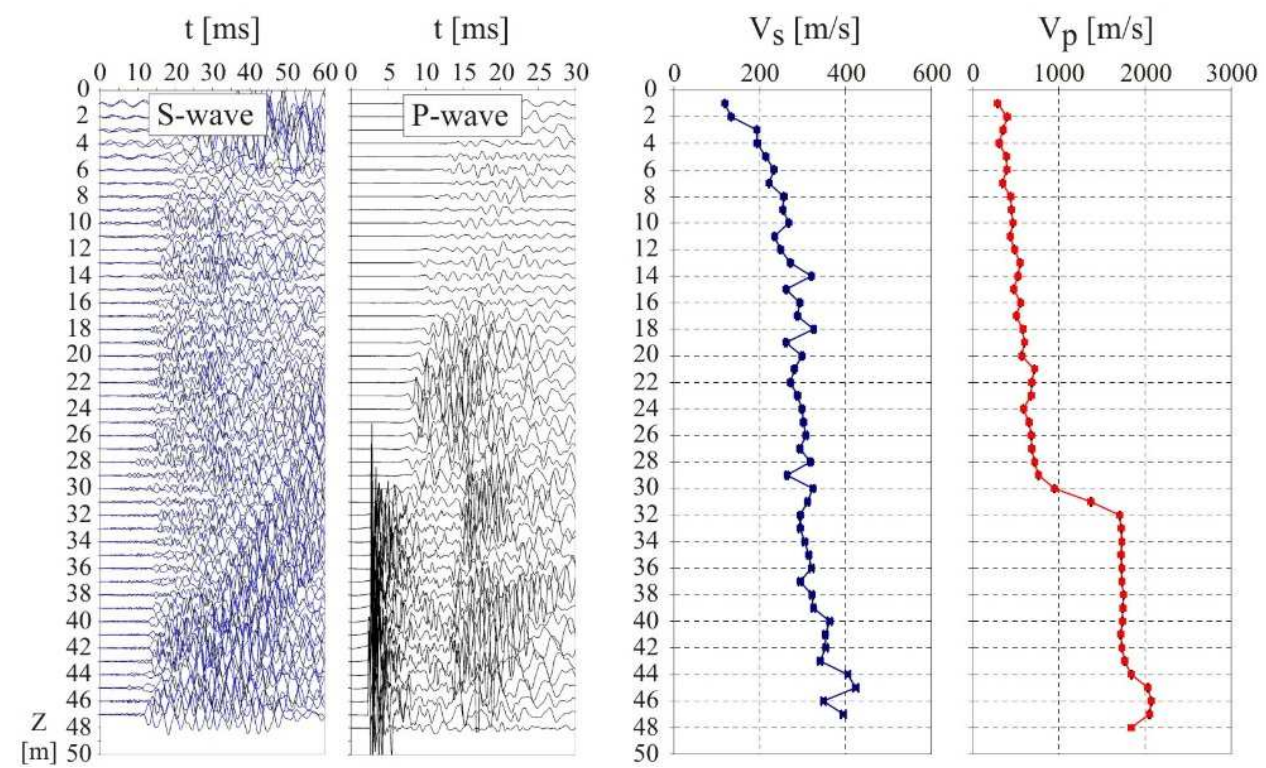

Fig. 8. Example of CHT results [6], (Z - depth).

The quality of the test results is controlled based on the analysis of the repeatability of the seismic signal expressed in a statistical measure of the variability of this survey. The ability to repeat the survey and select signals of the guaranteed quality minimizes measurement uncertainties associated with determining a reliable seismic wave velocity. The seismic measurement in the SDMT is also based on a replication test, though limited to the possibility of measuring only the shear wave velocity (Fig. 9).

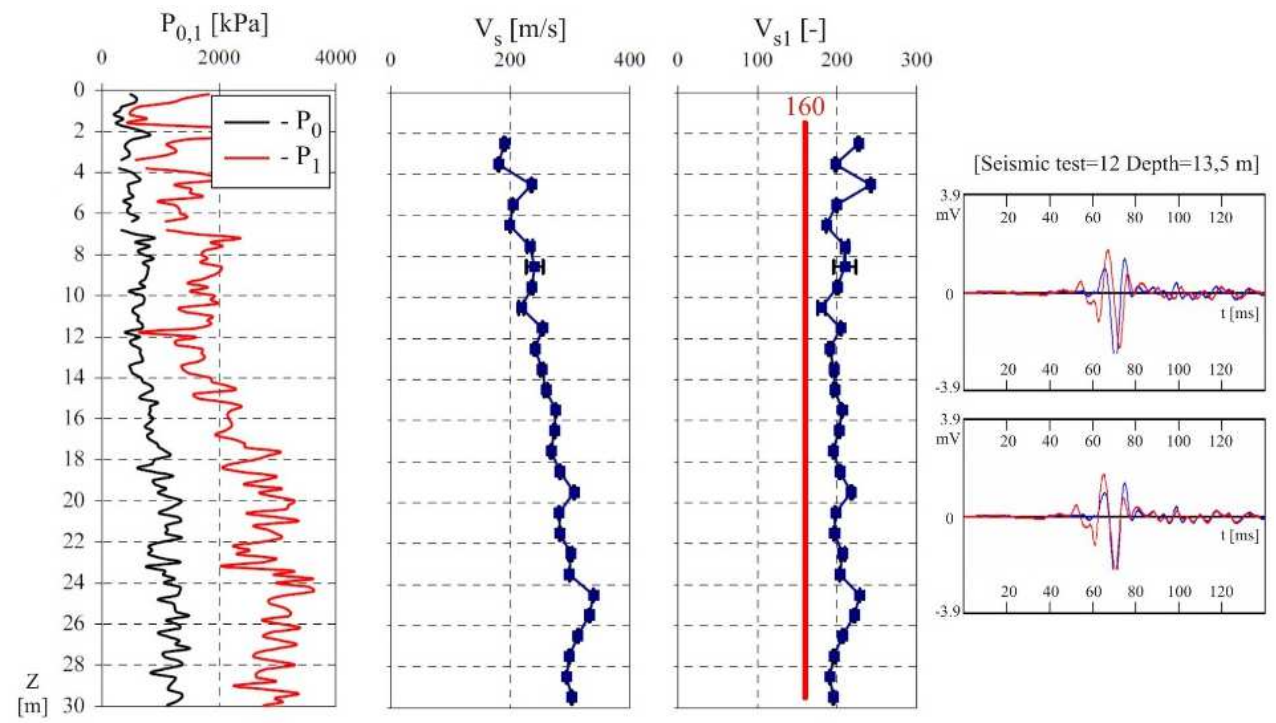

Fig. 9. Example of SDMT results [11], $\left(\mathrm{P}_{0}, \mathrm{P}_{1}\right.$-characteristics from DMT test).

The SCPTU allows to establish the velocity of two waves, shear and compression, on the basis of single measurement of the seismic signals and thus without the possibility of the statistical analysis (Fig. 10). 

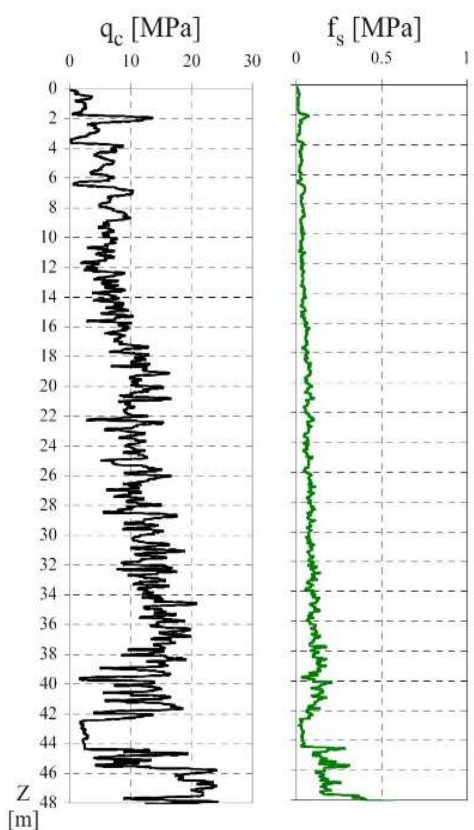
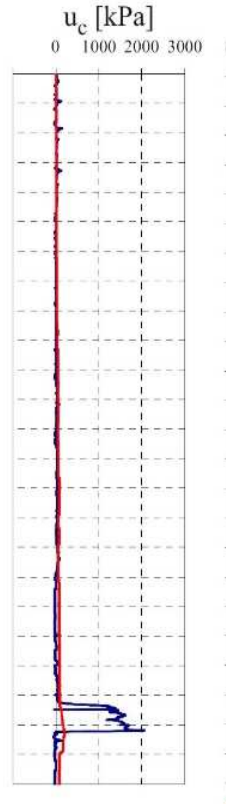

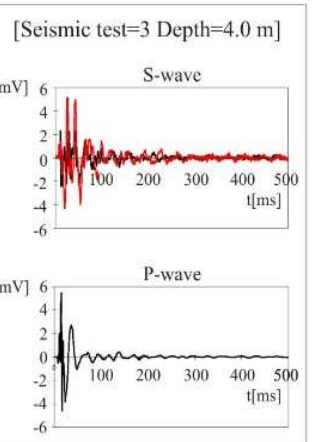

[Dissipation test $=5$ Depth $=44,4 \mathrm{~m}$ ]

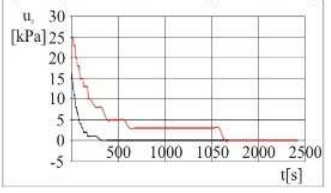

Fig. 10. Example of SCPTU results [11].

The results of the comparative analysis indicate that the velocity distributions of the seismic waves with the profile depth determined on the basis of different methods are strongly convergent (Fig. 11). This is confirmed by the results of the statistical analysis documenting the lack of statistical difference between the velocity distributions of the seismic waves determined by three independent methods. The biggest fluctuations in the velocity distribution of the shear wave with the profile depth with the repeatability of the seismic signal measurement expressed by the variation coefficient with values that do not exceed $1.5 \%$ are characteristic to the CHT. More even and overlapping distributions of the shear wave velocity with depth, with the quality of the seismic signal recorded with a dilatometer of an average variability coefficient of $2.0 \%$, were obtained from the cone penetration tests SCPTU and SDMT. An important factor affecting the results of the comparative analysis is the profile of the subsoil in which the test is conducted. In the case of a highly layered subsoil, which is constituted by deposited tailings, the penetration test (DHT), in which the propagation of seismic waves is measured vertically, generates a result that averages the velocity of the seismic wave passing through various layers of the soil on a small section limited by the location of geophones (usually $0,5 \mathrm{~m}$ ). Conversely, in the CHT, where the propagation of seismic waves is measured horizontally, the average measurement of the seismic wave velocity is determined by the local heterogeneity of the soil in a much larger space included in the conducted measurement. The above-mentioned impact of the subsoil heterogeneity on the seismic test methodology can be explained by local differences in the evaluation of the seismic wave velocities determined by the CHT and DHT.

Regarding the second question, the effectiveness of the test, it should be emphasized that in the CHT, the seismic test is a basic measurement while the DHT rather uses seismic tests as an additional testing method. In addition, the CHT requires much more financial and time expenditure compared to the DHT penetration testing.

According to the principles of the theory of elasticity, the results of the seismic wave velocity measurements can be used to estimate the initial shear and constrained modulus (equation 2 and 3): 
- initial shear modulus

$$
G_{0}=\rho\left(V_{s}\right)^{2}
$$

- initial constrained modulus

$$
M_{0}=\rho\left(V_{p}\right)^{2}
$$

where: $\rho$ - soil density, $V_{s}$ - velocity of shear wave, $V_{p}$ - velocity of compression wave.
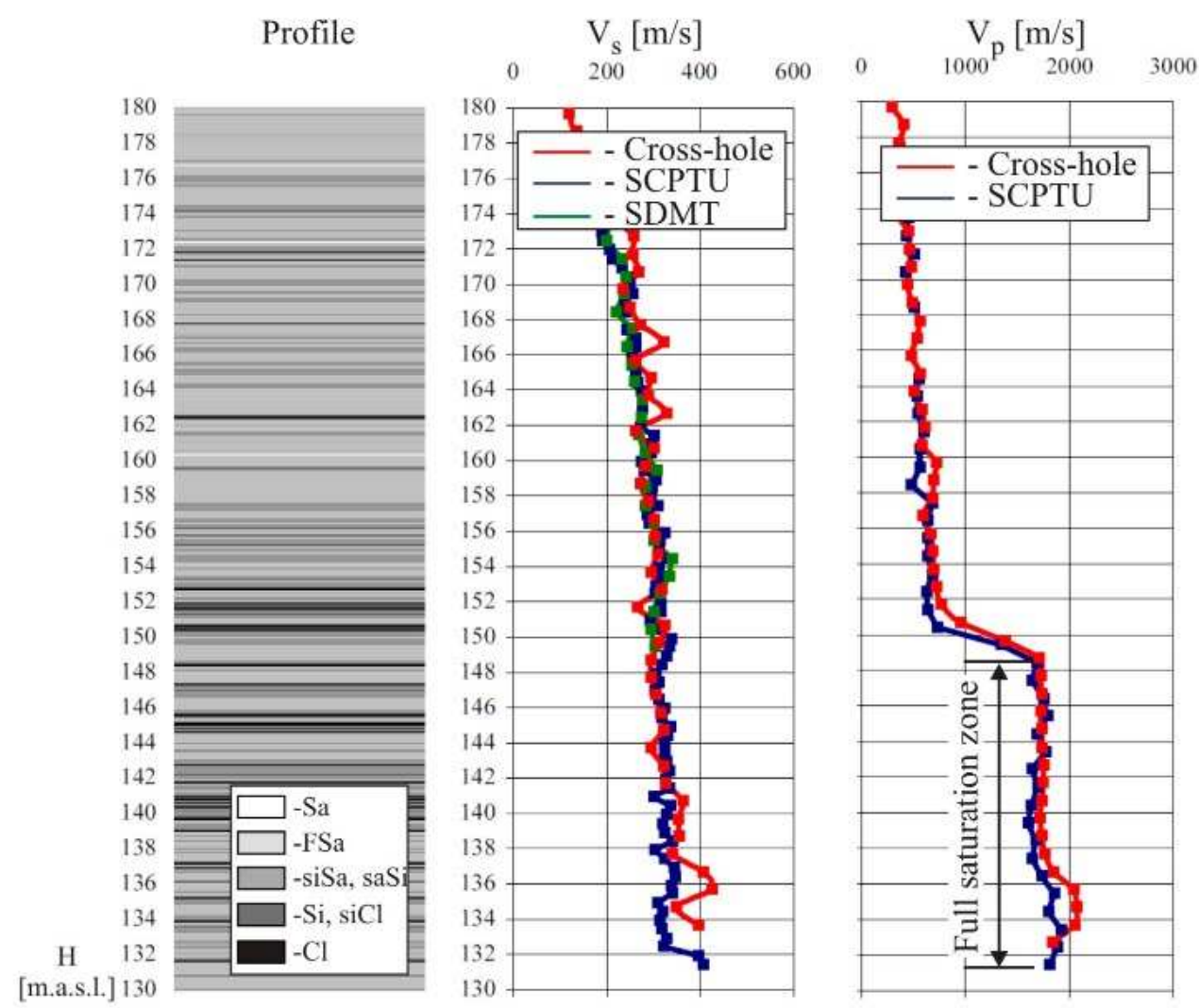

Fig. 11. Comparative analysis of tested methods [11].

Sample distributions of shear and constrained modulus calculated on the basis of the seismic wave velocities determined by the SCPTU are presented in Figure 12.

The soil density required to estimate the modulus values, which requires additional and independent testing in the case of the CHT. In competing DHT, the conventional classification systems based on penetration parameters (Fig. 9, Fig. 10), which are recorded in the standard CPTU and DMT, are used to determine the density of soils. On the basis of the same penetration parameters, using the original interpretation procedures and classification systems, continuous penetration characteristics of the subsoil are obtained in penetration studies including identification of physical, state, strength and deformation parameters, and, in the case of the CPTU testing, additional subsoil filtration parameters. The latter are determined on the basis of dissipation tests of excess pore pressure, the test carried out at the moment when cone penetration stops and when seismic measurements can be simultaneously carried out. 

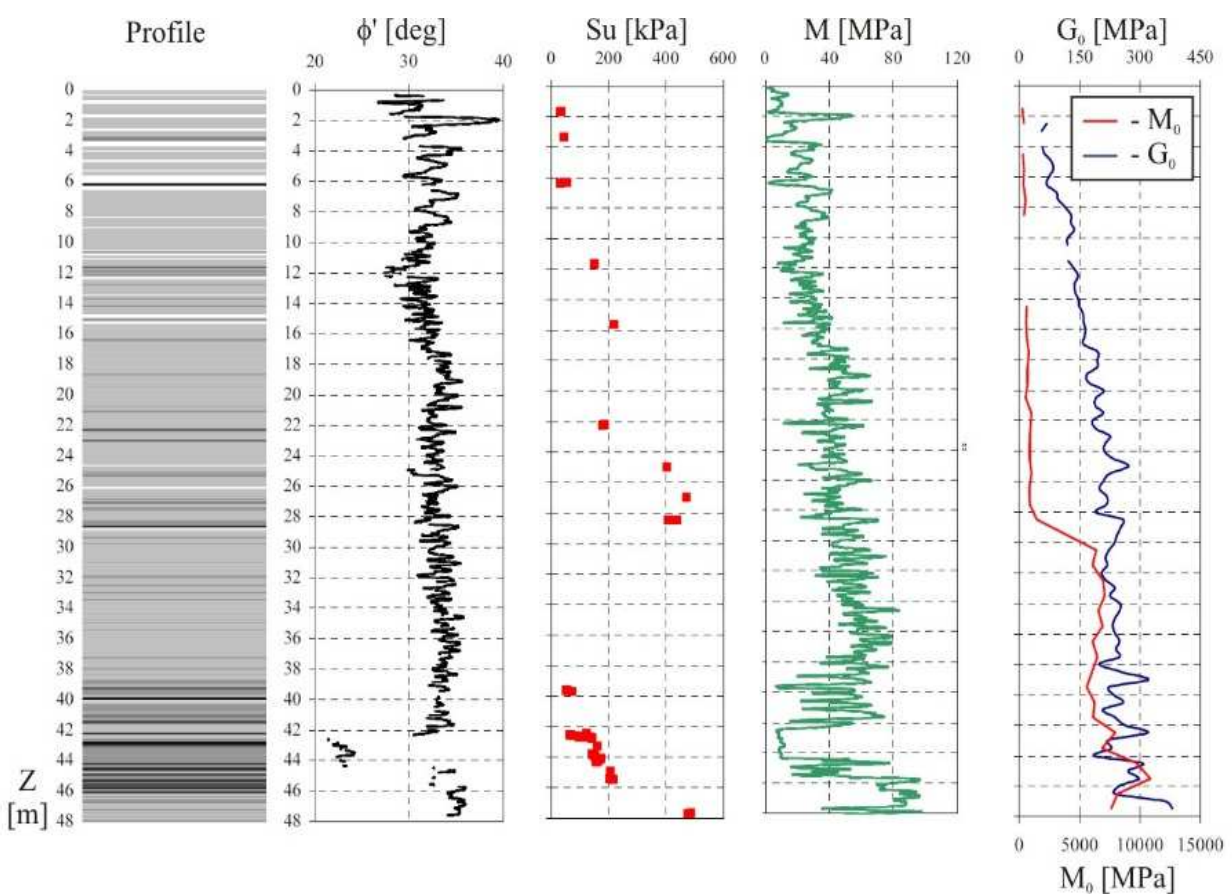

Fig. 12. Example of distribution of mechanical parameters from SCPTU, ( $\phi^{\prime}$ - effective friction angle, $\mathrm{Su}$ - undrained shear strength, $\mathrm{M}$ - constrained modulus).

Regardless of the implemented method of seismic tests, their result interpretation, tailings in particular, allows obtaining crucial information about the conditions in which the material was deposited. The first information is applied to resolve the scope of the full saturation zone of tailings, usually a zone of the least favorable strength characteristic. The full saturation zone is determined by the compression wave velocity of over $1550 \mathrm{~m} / \mathrm{s}$ (Fig. 11). The second important information is the identification of potential static liquefaction zones in the tailings massif. For this purpose, the distribution of the normalized shear wave with depth (equation 4) is analyzed and the potential hazard zone is identified by the normalized wave velocity less than $160 \mathrm{~m} / \mathrm{s}$ (Fig. 9).

$$
V_{s I}=V_{s}^{*}\left(\sigma_{v}^{\prime} / P a\right)^{-0,25}
$$

where: $V_{s}$ - shear wave velocity, $\sigma_{v}^{\prime}$ - effective vertical stress, $P a$-atmospheric pressure.

\section{Summary}

The calibration tests carried out using three methodologically different geophysical methods of seismic surveys and the analysis of their results showed that the statistical validity of the results of the tested methods is comparable. The method of choice, regardless of economic issues, should take into account preferences as well as limitations resulting from the type indicated to conduct the research. In the above context, the competitive methods are distinguished by the following characteristics presented in table 1 . 
Table 1. The advantages and limitations of CHT, SDMT and SCPTU.

\begin{tabular}{|c|c|c|}
\hline Method & Advantages & Limitations \\
\hline CHT & $\begin{array}{l}\text { - full statistical assessment of measurements quality, } \\
\text { - significant quality of preparatory works }\end{array}$ & $\begin{array}{l}\text { - significantly more } \\
\text { expensive tests as } \\
\text { compared to the down- } \\
\text { hole method }\end{array}$ \\
\hline SDMT & $\begin{array}{l}\text { - possibility of statistical assessment of measurements quality, } \\
\text { - characteristics from the penetration test }\left(\mathrm{p}_{0}, \mathrm{p}_{1}\right) \\
\text { - identification of soil deformation and shear strength } \\
\text { parameters, }\end{array}$ & $\begin{array}{l}\text { - no possibility to measu } \\
\text { compression wave } \\
\text { velocity }\left(V_{p}\right)\end{array}$ \\
\hline $\begin{array}{l}\text { SCPTU } \\
\text { (preferred } \\
\text { method) }\end{array}$ & $\begin{array}{l}\text { - possibility to determine velocity of } 2 \text { waves }\left(V_{s}, V_{p}\right) \text {, } \\
\text { - additional penetration characteristics }\left(q_{c}, f_{s}, u_{c}\right) \text {, } \\
\text { - full stratigraphic and parametric identification of subsoil, } \\
\text { - possibility to assess ground filtration capabilities, } \\
\text { - possibility to create correlations between penetration } \\
\text { parameters }-V_{s}, V_{p}=f\left(q_{c}, f_{s}, u_{c}\right)\end{array}$ & $\begin{array}{l}\text { - no possibility of } \\
\text { statistical analysis } \\
\text { of recorded signals }\end{array}$ \\
\hline
\end{tabular}

\section{References}

1. J. S. Lee, Geo-characterization using waves - Principle to application, Proc. of the $19^{\text {th }}$ Int. Conf. on Soil Mechanics and Geotechnical Engineering, 245-264 (2017)

2. M. Jamiolkowski, Role of geophysical testing in geotechnical site characterization, Proc. of the $3^{\text {rd }}$ De Mello Lecture, Portuguese-Brazilian Geotechnical Congress, Soils and Rocks 35, 2, 117-140 (2012)

3. H.L. Giacheti, R.A. Rodrigues, The seismic DMT in an unsaturated tropical soil, Proc. of the 19 $9^{\text {th }}$ Int. Conf. on Soil Mechanics and Geotechnical Engineering 1, 599-602 (2018)

4. M. Jamiolkowski, Soil mechanics and the observational method: challenges at the Zelazny Most copper tailings disposal facility, Geotechnique 64, 8, 590-619 (2014)

5. W. Tschuschke, Sondowania statyczne w odpadach poflotacyjnych (Cone penetration testing in mine tailings), Zeszyty Naukowe. Budownictwo, Politechnika Śląska, Gliwice (2006) (in Polish)

6. D. Milani, S. Priano, Zelazny Most Poland-Cross-Hole Tests, Report S16SN11-2. SolGeo Geophysical Solutions, Seriate, Italy (2017)

7. P. Mayne, Mc. Gillivray, Seismic piezocone and seismic flat dilatometer at Treporti, Proc. of the $2^{\text {nd }}$ Int. Conf. on Site Characterization 2, 1695-1700 (2002)

8. W. Tschuschke, G. Kmiecik, A. Mikos, Go profiling in mine tailings based on SCPTU and SDMT, Proc. of the $4^{\text {th }}$ Int. Conf. on Geotechnical and Geophysical Site Characterization 2, 1701-1706 (2013)

9. S. Marchetti, P. Monaco, G. Totani, D. Marchetti, In situ tests by seismic dilatometer (SDMT), Proc. from Research to Practice in Geotechnical Engineering, ASCE Geotech. Spec. Publ. 180, 292-311 (2008)

10. S. Gogolik, M. Waliński, Applicability of SDMT test in evaluating the modulus $G_{0}$ in tailings, Studia Geotechnica et Mechanica XXIX, 1-2, 39-46 (2007)

11. W. Tschuschke, S. Gogolik, Interpretation of Results of SCPTU and SDMT at the Mining Refuse Neutralization Facility Zelazny Most, Report 0281-2015/5, Poznan, Studio Geotechnika, Poland (2017) 